\title{
Presenting Characteristics and ICU Admission Among Patients Hospitalised with COVID-19
}

\author{
Aral Sürmeli1 (D), Öykü Beyaz² (D), Elif Sitre Koç² (D), Yasemin Gündoğdu² (D), Çağlar Çuhadaroğlu \\ Sesin Kocagöz 4 \\ ${ }^{1}$ Medical Rescue Association of Turkey, Istanbul, Turkey \\ 2 Department of Internal Medicine, Acıbadem Mehmet Ali Aydınlar University School of Medicine, İstanbul, Turkey \\ 3 Department of Chest Diseases, Acıbadem Mehmet Ali Aydınlar University School of Medicine, İstanbul, Turkey \\ 4 Department of Clinical Microbiology and Infectious Diseases, Acıbadem Mehmet Ali Aydınlar University School of \\ Medicine, Istanbul, Turkey
}

\begin{abstract}
Objective: Information on characteristics and outcomes of coronavirus disease 2019 (COVID-19) patients in Turkey is limited. We aimed to describe the characteristics and outcomes of patients hospitalised with COVID-19 and compare patients who required intensive care unit (ICU) admission with those who did not require it.

Materials and Methods: This retrospective cross-sectional study was conducted in a tertiary care hospital in Istanbul. A total of 215 patients hospitalised with COVID-19 between 9 March 2020 and 30 April 2020 were included. Demographic, clinical, laboratory and radiological data on admission and outcomes were analysed. The main outcomes were COVID-19 ward or ICU hospitalisation, invasive mechanical ventilation requirement, discharge, or death. Presenting characteristics were compared between patients who required ICU admission with those who did not require it.

Results: Among 215 patients, 64\% were male, and the median age was 53. The most prevalent comorbidity was hypertension, followed by diabetes mellitus and coronary artery disease. The prevalence of comorbidities and the median age was higher in patients in ICU. The most common presenting symptom was fever (\%72). C-reactive protein (CRP), lactate dehydrogenase (LDH), neutrophil and lymphocyte count, ferritin, and d-dimer levels were significantly different between ICU and non-ICU patients. However, in the final logistic model, among presenting symptoms, initial radiographs and laboratory tests, having dyspnea, high CRP and LDH were significantly associated with ICU admission.

Conclusion: Of 215 hospitalised patients with COVID-19, 17\% of patients required ICU admission, and the mortality rate was $4.4 \%$. Older age, having coronary artery disease, high levels of CRP, LDH, and presenting with dyspnea were significantly associated with ICU admission.
\end{abstract}

Keywords: infections, pneumonia, critical care

\section{Corresponding Author:} Aral Surmeli

E-mail:

a.surmeli@medak.org.tr

Received: January 28, 2021

Accepted: April 19, 2021

Published: April 30, 2021

\section{Suggested citation:}

Sürmeli A, Beyaz Ö, Koç ES, Gündoğdu Y, Çuhadaroğlu Ç, Kocagöz S. Presenting

Characteristics and ICU Admission Among Patients Hospitalised with COVID-19. Infect Dis Clin Microbiol 2021; 1: 14-21.

DOI: 10.36519/idcm.2021.20 


\section{INTRODUCTION}

T The novel coronavirus (SARS-CoV-2) started in December 2019 in China, has infected over 4.2 million people worldwide, resulting in a death toll of 290000 as of 13 May 2020 (1). It causes a multi-systemic infection named Coronavirus Disease 2019 (COVID-19) (2). The symptoms reported are non-specific and usually comprise fever, cough, dyspnea, and fatigue (3). The virus predominantly attacks the respiratory system, rendering some of the patients with respiratory distress (4). Even though some treatment guidelines exist and many randomized controlled trials are being conducted, no consensus on effective treatment modalities exists (5).

With a population of nearly 85 million people, Turkey is the 17th most populated country in the World. The Ministry of Health has been working to control the disease since the first confirmed case was declared in the country on 11 March 2020 (6, 7). A preliminary national COVID-19 guideline was released on 24 January, and it has been updated regularly according to emerging evidence (8). As of May 5, Turkey ranks nineth among the countries in the world in terms of total cases (9).

Istanbul, with its 15 million inhabitants, emerged as an epicentre for the COVID-19 pandemic (10). Over $60 \%$ of the COVID-19 cases in Turkey were situated in İstanbul (11). The risk of disease transmission is high, being the most populated city in Europe and hosting nearly 200,000 domestic and international passengers daily (12).

New local outbreaks are expected in the course of the pandemic, and thus, COVID-19 will continue to be a threat to the healthcare system. Matching with the clinical evidence, the bottleneck of managing this disease is the Intensive Care Units (ICU) capacity. One of the major determining factors on mortality for critically ill patients is the availability of the ICUs (13). Therefore, a strategic approach is necessary to help identify patients on their first admission who will most likely be in an ICU.

In this observational study, our objective was to describe demographic and clinical characteris- tics and outcomes of patients hospitalised with COVID-19 in a tertiary hospital in Istanbul. We compared patients who required ICU admission with those who did not require it and intended to inform clinicians and hospitals about the need for ICU admission among hospitalised patients.

\section{MATERIALS AND METHODS}

\section{Study design}

We performed a retrospective cross-sectional study at a large tertiary hospital in İstanbul. The hospital is designated as a pandemic centre throughout the COVID-19 outbreak, accepting all patients and serving free-of-charge as per the Turkish Ministry of Health regulations using the national COVID-19 treatment algorithm.

\section{The hospital capacity and COVID-I 9 adjustments} The hospital serves around 20000 patients per month with 50 ICU and 200 inpatient beds. Following the first confirmed COVID-19 case in Turkey on 11 March 2020, all attending staff were alerted and a 24-bed isolation ward for suspected and confirmed COVID-19 cases and 25 ICU beds with droplet and contact isolations were prepared. Another 24 beds were made available for the isolation ward afterwards. Against full ICU bed occupancy, 9 beds in the cardiac intensive care unit were also prepared. At the peak point of the COVID-19 outbreak, 48 beds in the wards and 25 beds in ICU were fully occupied. The hospital has not reached 100\% occupancy throughout the pandemic period and all patients requiring any level of care were taken care of.

\section{HIGHLIGHTS}

- Patients admitted to ICU because of COVID-19 were older, had more comorbidities, and presented with more severe symptoms and laboratory test results.

- Coronary artery disease was found to be a risk factor for higher morbidity due to COVID-19.

- High levels of CRP and LDH in initial tests were predictors of a higher risk of mortality and morbidity in patients hospitalized with COVID-19. 


\section{Participants}

We enrolled all adult patients who fulfilled confirmed or suspect COVID-19 case criteria according to the Ministry of Health Guidelines admitted to our hospital between 9 March 2020 and 30 April 2020.

\section{Data collection}

Data were collected from the electronic health record system of the hospital and the national COVID-19 surveillance system. During the COVID-19 outbreak, the national system was used in real-time for daily data collection of suspected or confirmed cases and contact tracing by the Ministry of HealthData included patients' sex, age, current smoking status, body mass index (BMI), comorbidities, presenting clinical signs and symptoms, initial laboratory tests, assessments of chest computed tomography (CT), final outcome (length of stay, discharge, mortality), prognoses on day 5, 10, 14, 21, and test result of real-time reverse transcription (RT)-polymerase chain reaction (PCR) from nasopharyngeal specimens.

Presenting clinical and laboratory parameters included temperature, respiratory rate, oxygen saturation, and heart rate; comorbidities included hypertension, diabetes mellitus, cardiovascular disease, chronic obstructive pulmonary disease (COPD), and asthma. Initial laboratory tests comprised complete blood count, C-reactive protein (CRP), ferritin, lactate dehydrogenase (LDH), d-dimer, interleukin-6, and CD4/8. Chest CT scan was defined as positive if the radiologist marked any sign of COVID-19 based on the existence of features consistent with pneumonia such as ground-glass opacities, consolidation, interlobular septal thickening. PCR test was regarded as positive if the patient had at least one positive result on consecutive tests.

The main outcome measures were the following: COVID-19 ward or ICU hospitalisation, the requirement of invasive mechanical ventilation, discharge or death. Mortality data were quite low (4.4\%), therefore not used as an endpoint in the analysis, but presented separately. A numeric scale ranging from 1 to 4 was developed to assess prognosis as follows: discharged, COVID-19 ward stay, ICU admission, ICU admission plus intubation.
The clinical outcome was evaluated on days 5, 10, 14, and 21 of the hospitalisation. The selection of these dates was based on the 5-day and 10-day regimens of treatment protocols and 14- and 21-days follow-up days recommended by the Turkish Ministry of Health COVID-19 treatment guideline. As of April 30, 2020, 26 patients were still hospitalised (12\% of the cases).

\section{Statistical Analysis}

Data were collected and aggregated on Microsoft Excel, and statistical analysis was performed on Stata. Continuous variables are presented as median (IQR), categorical variables are expressed as percentages (\%). For continuous variables, the difference in two groups (ICU and non-ICU patients) was analysed with a t-test if the distribution was normal and a Mann-Whitney test for non-normal distribution. Variables with small sample sizes were disregarded. In the analyses, a p-value less than 0.05 is used as the cut-off for significance for univariate analysis. For multivariable analysis logistic models with clinically and statistically significant variables (from univariate analysis) were used and known confounders were added. Iterative logistic modeling was used to produce the final model.

\section{RESULTS}

A total of 215 patients were included in the study. Among these, 186 had an outcome (death or discharge) at the end of the study period. For the remaining 29 patients, their current place of hospitalization (ICU with or without intubation or COVID-19 ward) was used. Of the 186 patients with an outcome, eight patients died (4.4\%), 32 patients (17\%) required ICU admission. Among ICU patients, 26 (15\% of the total population) were intubated. Twenty-nine people were still hospitalised at the time of analysis. Mortality was not used for outcome analysis because of a low number of events.

The median age was 53 (IQR: 41-64). Sixty-three per cent of the patients were male. The most prevalent comorbidity was hypertension (29.38\%), followed by coronary artery disease (16.43\%). The most common symptom was fever, with more than two out of three patients presenting with the symptom (Table 1). 
Table 1. Demographic and Baseline Characteristics of Patients

\begin{tabular}{|c|c|c|c|c|}
\hline & All patients $(n=215)$ & ICU $(n=38)$ & No ICU $(n=177)$ & $\mathrm{p}$-value ${ }^{1}$ \\
\hline ICU admission (\%) & 82.33 & & & \\
\hline Age (median, IQR) & $53(41-64)$ & $61(49-73)$ & $51(40-62)$ & 0.0014 \\
\hline Sex (male sex, \%) & 64 & 66 & 63 & 0.7280 \\
\hline Smoker $(\%)^{2}$ & 9.18 & 8.72 & 11.43 & 0.682 \\
\hline Hypertension $(\%)^{3}$ & 29.38 & 48.65 & 25.29 & $0.0042^{*}$ \\
\hline Diabetes Mellitus (\%) ${ }^{4}$ & 16.43 & 27.03 & 14.20 & 0.0541 \\
\hline $\operatorname{CAD}(\%)^{5}$ & 16.43 & 40.54 & 11.36 & $0.0001^{*}$ \\
\hline COPD/Asthma (\%) ${ }^{6}$ & 9.91 & 21.62 & 7.43 & $0.0081^{*}$ \\
\hline Obese or overweight ${ }^{7}(\%)$ & 65.73 & 70.37 & 64.90 & 0.5197 \\
\hline BMI (median, IQR) & $26.64(24.34-31.30)$ & $27.47(24.69-33.03)$ & $26.60(24.24-30.08)$ & 0.20 \\
\hline Most common symptom & Fever & Fever & Fever & \\
\hline Fever (\%) & 72.1 & 68.4 & 72.9 & 0.5757 \\
\hline Dyspnea (\%) & 28.4 & 60.5 & 21.5 & $0.0001^{*}$ \\
\hline Cough (\%) & 60.9 & 63.3 & 50 & 0.1373 \\
\hline Pulse (median, IQR) & $81.5(78-90)$ & $84(78-90)$ & $81(78-88)$ & 0.507 \\
\hline $\begin{array}{l}\text { Oxygen Saturation } \\
\text { (median, IQR)8 }\end{array}$ & 97 (96-98) & $95(92-97)$ & $97.5(97-98)$ & $0.0001^{*}$ \\
\hline Fever9 (\%) & 55.35 & 76.32 & 50.85 & 0.0043 \\
\hline
\end{tabular}

$1 \mathrm{P}$ values below 0.05 with 0.20 power calculation are marked with *.

${ }^{2}$ Active smokers at the time of admission.

${ }^{3} \mathrm{~A}$ clinical diagnosis of hypertension before the time of admission.

${ }^{4} \mathrm{~A}$ clinical diagnosis of diabetes mellitus Type 2 before the time of admission.

${ }^{5} \mathrm{~A}$ clinical diagnosis of coronary artery disease before the time of admission.

${ }^{6} \mathrm{~A}$ clinical diagnosis of COPD or asthma before the time of admission.

7 Defined as BMI over 25.0

8 Out of $\% 100$ saturation levels.

${ }^{9}$ This is objective fever measured from the axillary area and counted as positive if higher than 37.0 Celcius

The majority of patients had an outcome within ten days of their stay (68\%). The median day for ICU admission was 2.5 days ( $\mathrm{IQR}=2-5$ days, mean=3.4). The median day for intubation was 4 (IQR=3-7 days, mean=5.1) (Table 2).

\section{Comparison baseline characteristics and symp- toms of ICU and non-ICU patients}

The median age of patients who did not require ICU admission was 51 (IQR: 40-62), while the median age of patients who required ICU admission was 61 (IQR: 49-73), with a statistically significant difference. The proportion of men was $66 \%$ and $63 \%$ in ICU patients and non-ICU patients, respectively. However, no significant difference was found.

ICU patients' all parameters were higher than nonICU patients, except a fever higher than 37.0 Celsius. Besides, having coronary artery disease, hypertension, COPD or asthma were statistically significant. Diabetes mellitus was marginally insignificant $(\mathrm{p}=0.0541)$. In terms of presenting symptoms, ICU patients were significantly more likely to have dyspnea as compared to non-ICU patients (Table 1). 
Table 2. Length of hospitalisation

\begin{tabular}{|l|c|c|c|}
\hline $\begin{array}{c}\text { Length } \\
\text { of Stay }\end{array}$ & $\begin{array}{c}\text { No of } \\
\text { Patients }\end{array}$ & Percentage & $\begin{array}{c}\text { Cumulative } \\
\text { Percentage }\end{array}$ \\
\hline 5 days & 58 & $27 \%$ & $27 \%$ \\
\hline 10 days & 87 & $41 \%$ & $68 \%$ \\
\hline 14 days & 37 & $17 \%$ & $86 \%$ \\
\hline 21 days & 12 & $6 \%$ & $92 \%$ \\
\hline+21 days & 18 & $8 \%$ & $100 \%$ \\
\hline
\end{tabular}

\section{Laboratory variables and radiology}

Computed tomography was the main modality of radiography, with $94 \%$ of all admissions receiving at least once. Eighty-five per cent of all patients had some sort of sign in their CT, as evaluated by at least one radiologist. No further analysis of the difference in signs (e.g. the number of lobes involved) was done. Patients admitted to ICU were more likely to have a CT suggestive of COVID-19 or viral pneumonia than non-ICU patients with proportions of CT signs $92 \%$ and $82 \%$, respectively; however, the difference was not statistically significant. In univariable testing for laboratory parameters, all but thrombocyte count had a significant difference between ICU and non-ICU patients. Interleukin- 6 and CD4/8 values had too small a sample size for calculation (Table 3).

\section{Multivariate analysis of variables (Table 4)}

After adjusting for other values, significant variables were categorized with clinical evidence and previous literature. Having a CRP value of over 10 $\mathrm{mg} / \mathrm{dL}$ was related to 2.6 times the odds of being admitted to ICU. Similarly, having an LDH value of over $227 \mathrm{IU} / \mathrm{L}$ (normal value limit used in our hospital) was associated with 4.3 times the odds of being admitted to ICU. Only dyspnea among presenting symptoms was associated with a significant increase in odds of being admitted to ICU (OR:5.13).

\section{PCR results}

Serial PCR tests for the patient population revealed only three of them stayed PCR(-), $0.13 \%$ of the sample.

\section{Mortality}

Only eight patients have died during the follow-up (4.4\%). The median age of patients who died was 72 (IQR: 65-88). Six patients had hypertension as comorbidity, five were overweight, and all were admitted to ICU and intubated during hospitalization.

\section{DISCUSSION}

The main objective of this observational study is to describe the baseline and clinical characteristics of hospitalized COVID-19 patients in our hospital. Further, we describe the differences in variables between patients who required ICU admission and those who did not at any time during their hospitalization.

Patients who required ICU admission were significantly more likely to be older, have hypertension, COPD or asthma, and coronary artery disease than those who did not require ICU. Even though almost two-thirds of our patients were men, the proportion of women and men in the two groups were similar. The effects of age and having coronary artery disease remained statistically significant in multivariate analysis. Among the presenting symptoms, dyspnea emerged as significant in both univariate and multivariate analysis.

These findings corroborate with other published evidence from different countries. For example, studies from China (3) and the United States (14) have shown the effects of older age and comorbidities in deteriorating outcomes in COVID-19 patients. Similar to our findings, an independent association of coronary heart disease was found in a study in Wuhan, China, although with a different outcome, mortality (2).

Laboratory markers on admission also differed between the two groups of patients. Patients admitted to ICU had statistically significantly higher levels of CRP, LDH, neutrophil, D-dimer, and ferritin and low levels of lymphocyte. Multivariate analysis showed independent and significant effects of LDH and CRP after adjustment with age and sex. High levels of LDH and CRP on admission may be a useful marker to predict ICU admission. Other studies have reported the predictive value of varying factors for 
Table 3. Laboratory and Radiological Results

\begin{tabular}{|c|c|c|c|c|c|}
\hline & $\begin{array}{l}\text { Normal value } \\
\text { range }\end{array}$ & $\begin{array}{l}\text { All patients } \\
(n=215)\end{array}$ & ICU $(n=38)$ & No ICU $(n=177)$ & $\mathrm{p}$-value ${ }^{10}$ \\
\hline CRP (median) & $<0.5 \mathrm{mg} / \mathrm{dL}$ & 6.04 & 10.29 & 5.12 & $0.0001^{*}$ \\
\hline LDH (median) & $85-227 \mathrm{IU} / \mathrm{L}$ & 230 & 356.62 & 229.15 & $0.0001^{*}$ \\
\hline $\begin{array}{l}\text { Lymphocyte } \\
\text { (median) }\end{array}$ & $1.3-3.7610^{\wedge} 3 / \mathrm{uL}$ & 1.18 & 1.25 & 1.36 & $0.023^{*}$ \\
\hline $\begin{array}{l}\text { Thrombocyte } \\
\text { (median) }\end{array}$ & $150-439 \times 10^{\wedge} 3 / \mathrm{uL}$ & 202 & 248.87 & 213.14 & 0.5 \\
\hline $\begin{array}{l}\text { Neutrophile } \\
\text { (median) }\end{array}$ & $1.9-7 \times 10^{\wedge} 3 / \mathrm{uL}$ & 4.01 & 7.45 & 4.67 & $0.0001^{*}$ \\
\hline Ferritin (median) & $22-322 \mathrm{ng} / \mathrm{mL}$ & 200 & 552.5 & 248.0 & $0.0002^{*}$ \\
\hline D-dimer (median) & $0-0.5 \mathrm{mg} / \mathrm{L}$ & 0.64 & 1.46 & 0.56 & $0.0001^{*}$ \\
\hline $\begin{array}{l}\text { Interleukin-6 } \\
\text { (median) })^{11}\end{array}$ & $<7 \mathrm{pg} / \mathrm{mL}$ & 22.5 & 68.85 & 18.7 & \\
\hline $\mathrm{CD} 4 / 8$ (median) $^{12}$ & $0.8-3.9$ & 1.91 & 1.91 & 2.04 & \\
\hline CT positive (\%) & & 84.16 & 91.89 & 82.42 & 0.1540 \\
\hline
\end{tabular}

$10 \mathrm{p}$ values below 0.05 .

11 Insufficient sample size for significance calculation.

${ }^{12}$ Insufficient sample size for significance calculation.

disease progression. CRP, along with male sex, comorbidity, and lymphopenia, was shown as predicting severe outcomes in a study from China (15). In our group, lymphocyte count was significantly lower in the ICU patients. While this relationship did not hold in the multivariate analysis, it is an important parameter used by clinicians in our hospital for decision making and prognostic value.

Our study has several limitations. First, it is a descriptive analysis of patients who were hospitalized for COVID-19, and thus, the characteristics of patients who were isolated at home are not included. Second, this study was designed to investigate baseline characteristics and present clinical, laboratory, and radiological differences of ICU and nonICU patients. Therefore, analysis of changes in clinical and laboratory parameters in the disease course was not carried out. It should, however, be noted that although the progression of the disease can be quite different between patients, severe outcomes are usually seen in those who have a more serious clinical presentation on admission (16). Third, for some of the characteristics known to be a risk factor for deterioration of the disease, such as diabetes mellitus, we could not show statistical significance, most likely because of sampling size limitations.

However, the study has several strengths. We included all patients admitted with both suspect and confirmed COVID-19 infection to our hospital, decreasing the likelihood of missing cases which may be PCR (-) at the beginning of the infection. Indeed, results of follow-up tests among PCR (-) patients revealed that only three of them stayed PCR (-). Third, in terms of important comorbidities such as hypertension and diabetes mellitus, our study sample reflected the high levels seen in Turkey. This may have helped to increase the statistical power of our study despite the relatively small sample size. In addition, we used electronic records combining two databases to ensure completeness and accuracy of the records analysed. 
This is among the first studies from Turkey analysing the baseline and clinical characteristics and outcomes of hospitalised COVID-19 patients. Although our findings are similar to those described in previous studies from other countries, our patient population was younger than seen in other country settings (17), reflecting the relatively young age structure of the country.

\section{CONCLUSION}

COVID-19 pandemic is evolving worldwide while information on the virus, disease, and epidemiology of the disease is constantly changing. During a global pandemic, predictive values to anticipate the progress of the disease and triage accordingly are important to relieve the burden of the disease. This study presents and compares baseline characteristics of COVID-19 infected patients in ICU and non- ICU settings. In this rapidly evolving crisis, descriptive studies are of value to create more intervention side hypotheses. Our study found that having a coronary artery disease in the baseline, presenting with dyspnea, having high CRP and LDH
Table 4. Results of multivariate analysis

\begin{tabular}{|l|c|c|}
\hline & Odds Ratio & p-value \\
\hline $\mathrm{CRP}>10 \mathrm{mg} / \mathrm{dL}$ & 2.60 & $0.038^{*}$ \\
\hline $\mathrm{LDH}>227 \mathrm{IU} / \mathrm{L}$ & 4.18 & $0.003^{*}$ \\
\hline $\begin{array}{l}\text { Coronary Artery } \\
\text { Disease }\end{array}$ & 2.09 & 0.194 \\
\hline Chest CT & 3.60 & 0.081 \\
\hline Fever (subjective) & 1.9 & 0.27 \\
\hline Cough & 0.74 & 0.512 \\
\hline Dyspnea & 5.13 & $0.001^{*}$ \\
\hline
\end{tabular}

* $p$ values below 0.05

levels in the first laboratory results upon admission were associated with a higher probability of being admitted to ICU because of COVID-19 anytime during the hospital admission.
Ethical Approval: The Institutional Review Board of Acibadem Mehmet Ali Aydınlar University, School of Medicine (ATADEK) approved the study with the decision number of 2020-9/11.

Peer-review: Externally peer-reviewed

Author Contributions: Concept - A.S.; Design - Ö.B.; Supervision Y.G., E.K, Ç.C.; Fundings - S.K, C..Ç.; Materials - S.K.; Data Collection and/or Processing - A.S., Ö.B., E.K.; Analysis and/or Interpretation - S.K., E.K.; Literature Re-view - Y.G., S.K.; Writer - A.S., Ö.B., Y.G., E.K.; Critical Reviews - S.K., Ç.Ç.
Conflict of Interest: The authors have no conflict of interest to declare.

Financial Disclosure: The authors declared that this study has received no financial support.

Acknowledgements: We would like to thank Ahmet Şahin, MD, Rehile Zengin, MD, Gülseren Sağcan, MD, Hacer Kuzu Okur, MD, Davit Çukran, MD, Müjdat Kara, MD, Nalan Karadağ, MD, Ayşenur Özderya, MD and Figen Demir, MD for their support on this study.

\section{REFERENCES}

1 World Health Organization. Coronavirus disease 2019 (COVID-19): situation report. [cited 2020 May 15]. Available from: https:// www.who.int/docs/default-source/coronaviruse/situation-reports/20200513-covid-19-sitrep-114.pdf?sfvrsn=17ebbbe_4

2 Zhou F, Yu T, Du R, Fan G, Liu Y, Liu Z, et al. Clinical course and risk factors for mortality of adult inpatients with COVID-19 in Wuhan, China: a retrospective cohort study. Lancet 2020; 395: 1054-62.
3 Wang D, Hu B, Hu C, Zhu F, Liu X, Zhang J, et al. Clinical Characteristics of 138 Hospitalized Patients with 2019 Novel Coronavirus-Infected Pneumonia in Wuhan, China. JAMA 2020; 323: 1061-9.

4 Chen N, Zhou M, Dong X, Qu J, Gong F, Han Y, et al. Epidemiological and clinical characteristics of 99 cases of 2019 novel coronavirus pneumonia in Wuhan, China: a descriptive study. Lancet 2020; 395: 507-13. 
5 Pascarella G, Strumia A, Piliego C, Bruno F, Buono DR, Costa F, et al. COVID-19 diagnosis and management: a comprehensive review. J Intern Med 2020; 288: 192-206.

6 Worldometer 2020. [cited 2020 May 19]. Available from: https://www.worldometers.info/worldpopulation/population-by-country/

7 McKernan, B. Turkey announces its first case of coronavirus. [cited 2020 May 19]. Available from: https://www.theguardian.com/ world/2020/mar/11/turkey-announces-its-first-case-of-coronavirus

8 Turkish Ministry of Health. COVID-19 (SARS-CoV-2 enfeksiyonu) rehberi. [cited 2020 May 19]. Available from: https://covid19bilgi.saglik.gov.tr/depo/rehberler/COVID-19_Rehberi.pdf.

9 Coronavirus Update (Live): 4,924,383 Cases and 320,816 Deaths from COVID-19 Virus Pandemic. [cited 2020 May 19] Available from: https://www.worldometers.info/coronavirus/\#countries.

10 Türkiye İstatistik Kurumu, Adrese Dayalı Nüfus Kayıt Sistemi Sonuçlan, 2017. [cited 2020 May 19]. Available from: http://www.tuik.gov.tr/PreHaberBultenleri.do;jsessionid=8FJDhyCWQJ1zgWYwrsL131DbCfbhxRc56SbHK4rTJR1M$\underline{\text { rBSTVSC1! } 116535747 ? \mathrm{id}=27587}$
11 Istanbul Metropolitan Municipality. Koronavirüs 2020. [cited 2020 May 19]. Available from: https://koronavirus.ibb.istanbul/

12 World Population Review. Europe Cities by Population 2020. [cited 2020 May 19]. Available from: https://worldpopulationreview.com/continents/cities-in-europe/

13 Immovilli P, Morelli N, Antonucci E, Radaelli G, Barbera M, Guidetti D. COVID-19 mortality and ICU admission: the Italian experience. Crit Care 2020; 24: 228.

14 Richardson S, Hirsch JS, Narasimhan M, Crawford JM, McGinn T, Davidson KW, et al. Presenting Characteristics, Comorbidities, and Outcomes Among 5700 Patients Hospitalized With COVID-19 in the New York City Area. JAMA 2020; 323: 2052-9.

15 Zhang J, Yu M, Tong S, Liu LY, Tang LV. Predictive factors for disease progression in hospitalized patients with coronavirus disease 2019 in Wuhan, China. J Clin Virol 2020; 127: 104392.

16 Docherty AB, Harrison EM, Green CA, Hardwick H, Pius R, Norman L, et al. Features of 16,749 hospitalised UK patients with COVID-19 using the ISARIC WHO Clinical Characterisation Protocol. medRxiv [ preprint] 2020: 2020.04.23.20076042.

17 Myers LC, Parodi SM, Escobar GJ, Liu VX. Characteristics of Hospitalized Adults With COVID-19 in an Integrated Health Care System in California. JAMA 2020; 323: 2195-8. 